\title{
nutrients
}

ISSN 2072-6643

www.mdpi.com/journal/nutrients

Article

\section{Risk of Suboptimal Iodine Intake in Pregnant Norwegian Women}

\author{
Anne Lise Brantsater ${ }^{1{ }_{*},}$, Marianne Hope Abel ${ }^{2}$, Margaretha Haugen ${ }^{1}$ and \\ Helle Margrete Meltzer ${ }^{1}$
}

1 Department of Exposure and Risk Assessment, Division of Environmental Medicine, Norwegian Institute of Public Health, P.O. Box 4404, Nydalen, NO-0403, Norway;

E-Mails: Margaretha.Haugen@fhi.no (M.H.); Helle.Margrete.Meltzer@fhi.no (H.M.M.)

2 Tine SA Oslo Norway, P.O. Box 25, 0051 Oslo, Norway; E-Mail: Marianne.Hope.Abel@tine.no

* Author to whom correspondence should be addressed; E-Mail: Anne.Lise.Brantsaeter@fhi.no; Tel.: +47-21076326; Fax: +47-21076243.

Received: 23 November 2012; in revised form: 18 December 2012 / Accepted: 28 January 2013 / Published: 6 February 2013

\begin{abstract}
Pregnant women and infants are exceptionally vulnerable to iodine deficiency. The aims of the present study were to estimate iodine intake, to investigate sources of iodine, to identify predictors of low or suboptimal iodine intake (defined as intakes below $100 \mu \mathrm{g} /$ day and $150 \mu \mathrm{g}$ /day) in a large population of pregnant Norwegian women and to evaluate iodine status in a sub-population. Iodine intake was calculated based on a validated Food Frequency Questionnaire in the Norwegian Mother and Child Cohort. The median iodine intake was $141 \mu \mathrm{g} / \mathrm{day}$ from food and $166 \mu \mathrm{g} / \mathrm{day}$ from food and supplements. Use of iodine-containing supplements was reported by $31.6 \%$. The main source of iodine from food was dairy products, contributing $67 \%$ and $43 \%$ in non-supplement and iodine-supplement users, respectively. Of 61,904 women, 16.1\% had iodine intake below $100 \mu \mathrm{g} /$ day, 42.0\% had iodine intake below $150 \mu \mathrm{g} /$ day and only $21.7 \%$ reached the WHO/UNICEF/ICCIDD recommendation of $250 \mu \mathrm{g} /$ day. Dietary behaviors associated with increased risk of low and suboptimal iodine intake were: no use of iodine-containing supplements and low intake of milk/yogurt, seafood and eggs. The median urinary iodine concentration measured in 119 participants $(69 \mu \mathrm{g} / \mathrm{L})$ confirmed insufficient iodine intake. Public health strategies are needed to improve and secure the iodine status of pregnant women in Norway.
\end{abstract}


Keywords: iodine; pregnancy; prospective cohort; food frequency questionnaire; the Norwegian Mother and Child Cohort Study (MoBa)

\section{Introduction}

Iodine is an essential component of the thyroid hormones. It is required throughout the life-cycle and is obtained primarily through the diet. Iodine deficiency is the world's greatest single cause of preventable brain damage, and in the last few decades, there has been remarkable progress in the global effort to eliminate iodine deficiency [1-3]. Insufficient iodine status is not only a problem in developing countries, but is also characterized as a major public health problem in many countries in Europe and the Western world [1,4-6].

Before 1950, there was endemic iodine deficiency in Norway, with goiter prevalence as high as $80 \%$ in certain inland areas [7]. Since then, iodine has been added to cow fodder, resulting in a relatively high concentration of iodine in milk and dairy products. Combined with a high consumption of milk and other dairy products, this led to eradication of endemic goiter [8]. The same happened in Britain [9], while other countries introduced national iodization programs by adding iodine to salt $[5,10]$.

Pregnant women and infants are exceptionally vulnerable to deficiency, because iodine is essential for normal fetal and child brain development and growth [4,11]. The estimated average requirement for iodine in non-pregnant adults is $95 \mu \mathrm{g} /$ day, and the recommended intake of $150 \mu \mathrm{g} / \mathrm{day}$ is derived by adding $2 \mathrm{SD}$ and rounding to the nearest $50 \mu \mathrm{g} / \mathrm{day}[3,5]$. The estimated average requirement is increased by at least $50 \%$ during pregnancy and lactation $[3,12]$. The recommended iodine intake during pregnancy is $175 \mu \mathrm{g}$ /day in Nordic countries [13], while WHO/UNICEF/ICCIDD recommends $250 \mu \mathrm{g}$ /day during pregnancy and lactation [14]. According to the epidemiological criteria for assessment of iodine status in pregnant populations, a median urinary iodine concentration (UIC) below $150 \mu \mathrm{g} / \mathrm{L}$ defines iodine deficiency (insufficient iodine intake), while a median UIC in the range $150-249 \mu \mathrm{g} / \mathrm{L}$ defines adequate (optimal) iodine intake $[3,14,15]$. Iodine deficiency during pregnancy is of concern when iodine intake falls below $100 \mu \mathrm{g} / \mathrm{day}[16]$.

Iodine deficiency has not been considered an issue in developed countries, such as Norway, for many decades. However, a sub-study in 119 pregnant women recruited to the Norwegian Mother and Child Cohort study (MoBa) in 2003-2004 revealed low iodine intake [17,18]. Low iodine intake was also seen in a study within a larger sample of MoBa, with $10 \%$ of the women having iodine intake below $70 \mu \mathrm{g} /$ day [19]. Studies on iodine intake and iodine status of pregnant women are urgently needed.

There have been major changes in Norwegian food patterns over the last decades. The aims of the present study were to estimate iodine intake, to investigate sources of iodine, to identify predictors of low or suboptimal iodine intake (defined as intakes below $100 \mu \mathrm{g} /$ day and $150 \mu \mathrm{g}$ /day, respectively) in a large population of pregnant Norwegian women and to evaluate iodine status in a sub-population of the participants. 


\section{Materials and Methods}

\subsection{Population and Study Sample}

The data set is part of the Norwegian Mother and Child Cohort study (MoBa), a prospective population-based pregnancy cohort conducted by the Norwegian Institute of Public Health [20]. Participants were recruited from all over Norway from 1999 to 2008, and 38.5\% of invited women consented to participate. The cohort now includes 108,000 children, 90,700 mothers and 71,500 fathers. Blood samples were obtained from both parents during pregnancy and from mothers and children (umbilical cord) at birth. Follow-up is conducted by questionnaires at regular intervals and by linkage to national health registries. Several sub-studies are conducting additional collections of data and biological materials.

The data included in this study are from two questionnaires answered in gestational weeks 15 (Q1) and 17-22 (Q2), respectively. Q2 is a detailed food frequency questionnaire (FFQ), while Q1 is a general questionnaire covering health, exposures, lifestyles and background factors. Pregnancy and birth records from the Medical Birth Registry of Norway (MBRN) are linked to the MoBa database [21]. Informed consent was obtained from each participant before the study. The study was approved by the Regional Committee for Ethics in Medical Research and the Data Inspectorate in Norway.

This study uses the quality-assured data files released for research in 2009 (version 4). At the time of this analysis, 89,656 women had answered the first MoBa questionnaire and were recorded in MBRN. Of these, 76,218 had also answered version 2 of the FFQ [22], and 74,914 had registered a valid food intake (total energy $>4500 \mathrm{~kJ}$ and $<20,000 \mathrm{~kJ}$ per day). The range of acceptable energy intake in $\mathrm{MoBa}$ has been evaluated elsewhere [22]. We excluded 5447 participants with missing information on maternal height, weight, smoking habits, educational attainment or household income and 7563 women who had participated in MoBa with more than one pregnancy, resulting in a study sample of 61,904 women for analysis.

Finally, we included data from a subpopulation of 119 women who participated in a validation study of the MoBa FFQ. While data on urinary iodine levels in this sub-sample have previously been reported as $24 \mathrm{~h}$ urinary iodine excretion (UIE, $\mu \mathrm{g} / 24 \mathrm{~h}$ ), the current study presents these results as urinary iodine concentration (UIC, $\mu \mathrm{g} / \mathrm{L}$ ). While UIE was relevant for validating estimated iodine intake, UIC is relevant for evaluating iodine status [14]. Details about the study population, urinary sampling and iodine analysis have been described in detail previously [17,18]. Participants in the validation study sub-sample were not representative of all women in MoBa. However, the estimated iodine intake and sources of iodine were similar to the whole cohort [17].

\subsection{Dietary Information}

The MoBa FFQ [23] was specifically planned for the MoBa study and was completed by participating women in gestational weeks 17 to 22 . The dietary data used in this study were collected from February 2002 to November 2008. The MoBa FFQ is a semi-quantitative questionnaire designed to capture dietary habits and intake of dietary supplements during the first four to five months of pregnancy and included questions about intake of 255 food items or dishes [22]. For each food item, 
the frequency of consumption was reported by selecting one out of 8-10 frequencies, ranging from never to several times monthly, weekly or daily. Consumption frequencies were converted into food amounts (g/day) by the use of standard Norwegian portion sizes. Food and nutrient calculations were performed with FoodCalc [24] and the Norwegian food composition table [25]. For calculation of dietary iodine, we used available data from analyses of Norwegian milk and food samples [26,27]. Food items in the FFQ were combined into non-overlapping groups, and the contribution of the various food groups to iodine intake was computed.

The FFQ did not include any question about the use of table salt or use of iodine fortified table salt. In Norway, few brands of table salt are iodized (maximum $5 \mu \mathrm{g} / \mathrm{g} \mathrm{NaCl}$ ), and the use of this salt is limited to private households and not allowed in the food industry [27]. Drinking water in Norway contains only negligible amounts of iodine $(\sim 2 \mu \mathrm{g} / \mathrm{L})$ [27].

The last page in the FFQ asked about use of food supplements. Thirteen commonly used vitamin, mineral and cod liver oil/fish oil supplements were pre-coded and followed by 6 open-ended spaces where the women were asked to record the name and manufacturer of the supplement(s) used, but not listed. The frequency was reported as one of 9 options of weekly use (never, $<1$ and $1-7$ ) and the quantity was reported as one of 3 options for liquid supplements and one of 4 options for number(s) of tablets/capsules $(1,2,3$ and $\geq 4)$. For calculating nutrients from dietary supplements, an Access database (Microsoft Office 2003) containing the nutrient value of more than 1000 different food supplements was constructed. Commonly sold food supplements in Norway were registered by information provided by the manufacturer, whereas nutritional information of dietary supplements bought from the Internet or abroad were collected from the Internet, either found on the homepage of the manufacturer or the supplier [19].

A validation study showed that, relative to a dietary reference method and several biological markers, the MoBa FFQ produces a realistic estimate of habitual intake and is a valid tool for ranking pregnant women according to high and low intakes of energy, nutrients and foods [28]. The relative validity of iodine intake from food and supplements and the intake of specific food groups, such as dairy products and seafood, was evaluated separately. Total iodine intake by the FFQ showed acceptable agreement with iodine intake by the food diary $(r=0.48,95 \%$ CI: $0.33,0.61)$ and with urinary iodine excretion $(r=0.42,95 \% \mathrm{CI}: 0.26,0.56)$. Urinary iodine excretion reflected the important food sources and whether or not iodine was contributed by supplements [17,18,29]. Women were recruited to the validation study between January 2003 and February 2004, and a seasonal difference in urinary iodine excretion reflected a seasonal difference in the iodine content of Norwegian milk [17].

The intake of all types of milk and yogurt, except that used in mixed dishes, was divided in several ways: first, into three categories ( $<200 \mathrm{~mL} /$ day, $200-399 \mathrm{~mL} /$ day and $\geq 400 \mathrm{~mL} /$ day); second, into six groups ( $<100 \mathrm{~mL} /$ day, $100-199 \mathrm{~mL} /$ day, 200-299 mL/day, 300-399 mL/day, 400-499 mL/day and $\geq 500 \mathrm{~mL} /$ day); and third, into two categories ( $<200 \mathrm{~mL} /$ day or $\geq 200 \mathrm{~mL} /$ day). The intake of seafood was divided first into five groups ( $<5 \mathrm{~g} /$ day, 5-19 g/day, 20-39 g/day, 40-59 g/day and $\geq 60 \mathrm{~g} /$ day) and, second, into two categories ( $<20 \mathrm{~g} /$ day or $\geq 20 \mathrm{~g} /$ day). Egg intake was divided into two categories $(<8 \mathrm{~g} /$ day or $\geq 8 \mathrm{~g}$ /day). Total energy intake was treated as a continuous variable. 


\subsection{Other Variables}

Maternal age at delivery was divided into four categories $(<25,25-29,30-34$ and $\geq 35$ years). Marital status was divided into two categories (married/cohabiting or single). Self-reported pre-pregnancy height and weight were used to calculate body mass index $\left(\mathrm{kg} / \mathrm{m}^{2}\right)$, which was divided into WHO categories $\left(<18.5,18.5-24.9,25-29.9\right.$ and $\left.\geq 30 \mathrm{~kg} / \mathrm{m}^{2}\right)$, length of education into three categories $(\leq 12,13-16$ or $\geq 17$ years), total household income into three categories (both participant and her partner $<\mathrm{NOK} 300,000$, one $\geq \mathrm{NOK} 300,000$ or both partners $\geq \mathrm{NOK} 300,000$ ) and pre-pregnant smoking in three categories (non-smokers, occasional smokers or daily smokers). Parity was divided into three categories (nulliparous, primiparous or multiparous).

\subsection{Statistical Methods}

The estimated intakes of iodine from food and supplements were skewed and are presented by the median and the 5th and 95th percentiles (P5, P95). For univariate analyses, we used the Mann-Whitney $U$ test for two group comparisons and the Kruskall-Wallis test for multiple group comparisons of iodine intakes. We used multiple logistic regression analysis to identify predictors of low and suboptimal iodine intake and present crude and adjusted odds ratios (OR) with $95 \%$ confidence intervals (CIs). Maternal characteristics and lifestyle variables examined as potential predictors were: maternal age, parity, education, marital status, smoking, pre-pregnancy BMI, household income, iodine containing supplement use and intakes of milk and yogurt, eggs and seafood. As iodine from food increased with increasing food intake, we adjusted for total energy intake. The significance level was set at 5\% (two-tailed), and all analyses were performed using the statistical software PASW statistics 17 (SPSS Inc., IBM Company, Chicago, IL, USA).

\section{Results}

The median intake of iodine from food was $141 \mu \mathrm{g} /$ day, and the median total intake from food and supplements was $166 \mu \mathrm{g} /$ day. Iodine was obtained from supplements in 19,575 (31.6\%) of the women, and the median intake contributed by supplements in this group was $107 \mu \mathrm{g} / \mathrm{day}$, resulting in a median total intake of $252 \mu \mathrm{g} /$ day in iodine supplement users. Very low iodine intake $(<70 \mu \mathrm{g} /$ day $)$ was observed for $4.8 \%$, low intake $(<100 \mu \mathrm{g}$ /day) for $16.1 \%$ and suboptimal intake $(<150 \mu \mathrm{g} /$ day $)$ was observed for $42 \%$ of all participants. The prevalence of low and suboptimal intake was much higher in women who did not obtain iodine from supplements (Table 1). In the total group, 54.3\% had iodine intakes $<175 \mu \mathrm{g} /$ day, while the proportion was $70.5 \%$ in non-iodine supplement users. In the upper end of iodine intake, two women had intakes above $1100 \mu \mathrm{g}$ /day, which is considered the upper limit of intake that is unlikely to cause adverse health effects, while 770 women (1.2\%) had excessive intakes ( $\geq 500 \mu \mathrm{g} / \mathrm{day})$. 
Table 1. Iodine intake in 61,904 pregnant Norwegian women in the Norwegian Mother and Child Cohort Study, 2002-2008.

\begin{tabular}{|c|c|c|c|c|c|c|c|}
\hline \multirow{4}{*}{$\frac{n(\%)}{\text { Iodine intake, } \mu \mathrm{g} / \text { day }}$} & \multirow{2}{*}{\multicolumn{3}{|c|}{ All }} & \multicolumn{4}{|c|}{ Iodine containing supplement user } \\
\hline & & & & \multirow{2}{*}{\multicolumn{2}{|c|}{$\begin{array}{c}\text { No } \\
42,329(68.4) \\
\end{array}$}} & \multirow{2}{*}{\multicolumn{2}{|c|}{$\begin{array}{c}\text { Yes } \\
19,575(31.6) \\
\end{array}$}} \\
\hline & & 61,90 & & & & & \\
\hline & $n$ & $\%$ & Cum\% & $n$ & Cum\% & $n$ & Cum\% \\
\hline$<50$ & 674 & 1.1 & 1.1 & 667 & 1.6 & 7 & 0.0 \\
\hline $50-70$ & 2272 & 3.7 & 4.8 & 2208 & 6.8 & 64 & 0.4 \\
\hline $70-100$ & 7006 & 11.3 & 16.1 & 6658 & 22.5 & 348 & 2.1 \\
\hline $100-150$ & 16,061 & 25.9 & 42.0 & 14,267 & 56.2 & 1794 & 11.3 \\
\hline $150-175$ & 7572 & 12.2 & 54.3 & 6044 & 70.5 & 1528 & 19.1 \\
\hline $175-250$ & 14,886 & 24.0 & 78.3 & 8970 & 91.7 & 5916 & 49.3 \\
\hline $250-500$ & 12,663 & 20.5 & 98.8 & 3463 & 99.9 & 9200 & 96.3 \\
\hline$\geq 500$ & 770 & 1.2 & 100 & 52 & 100 & 718 & 100 \\
\hline
\end{tabular}

Iodine from food did not differ with regard to maternal age, education, use of supplements or marital status, but was lower in smokers than in non-smokers and higher in multiparous than in nulliparous women. Total iodine intake was also higher in nulliparous women than in parous women. Total iodine decreased with increasing BMI, but the negative association was confounded by total energy intake and disappeared when energy was taken into account (data not shown). The most outstanding differences in iodine intakes were found with regards to differences in milk, seafood and egg consumption and whether or not iodine was obtained from supplements (Table 2).

Table 2. Iodine intake, median and range (5th percentile, 95th percentile) by maternal characteristics.

\begin{tabular}{|c|c|c|c|c|c|}
\hline & & Iodine from food & & Total iodine & \\
\hline & $n(\%)$ & $\begin{array}{c}\text { Median (P5, P95) } \\
\mu \mathrm{g} / \text { day }\end{array}$ & $p$-Value * & $\begin{array}{c}\text { Median (P5, P95) } \\
\mu \mathrm{g} / \text { day }\end{array}$ & $p$-Value * \\
\hline All & 61,904 & $141(65,280)$ & & $166(71,369)$ & \\
\hline \multicolumn{6}{|l|}{ Maternal age } \\
\hline$<25$ years & $6880(11.1)$ & $141(61,305)$ & \multirow{4}{*}{0.406} & $164(65,389)$ & \multirow{4}{*}{0.207} \\
\hline 25-29 years & $20,926(38.3)$ & $141(64,282)$ & & $167(70,373)$ & \\
\hline 30-34 years & $23,554(38.0)$ & $141(66,274)$ & & $165(73,362)$ & \\
\hline$\geq 35$ years & $10,544(17.0)$ & $141(67,275)$ & & $166(74,367)$ & \\
\hline \multicolumn{6}{|l|}{ Parity } \\
\hline Nulliparous & $32,053(51.8)$ & $139(64,280)$ & \multirow{3}{*}{$<0.001$} & $169(71,381)$ & \multirow{3}{*}{$<0.001$} \\
\hline Primiparous & $19,262(31.1)$ & $141(65,279)$ & & $162(70,357)$ & \\
\hline Multiparous & $10,589(17.1)$ & $147(67,284)$ & & $164(72,356)$ & \\
\hline \multicolumn{6}{|c|}{ Maternal education } \\
\hline$\leq 12$ years & $19,809(32.0)$ & $140(60,295)$ & \multirow{3}{*}{0.607} & $163(65,372)$ & \multirow{3}{*}{$<0.001$} \\
\hline $13-16$ years & $26,612(43.0)$ & $141(66,276)$ & & $167(73,369)$ & \\
\hline$\geq 17$ years & $15,484(25.0)$ & $141(70,267)$ & & $167(76,366)$ & \\
\hline
\end{tabular}


Table 2. Cont.

\begin{tabular}{|c|c|c|c|c|c|}
\hline \multicolumn{6}{|l|}{ Marital status } \\
\hline Married/cohabiting & $59,726(96.5)$ & $141(65,279)$ & \multirow{2}{*}{0.083} & $166(71,368)$ & \multirow{2}{*}{0.246} \\
\hline Not married/cohabiting & $2178(3.5)$ & $143(61,302)$ & & $168(67,388)$ & \\
\hline \multicolumn{6}{|c|}{ Smoking prior to pregnancy } \\
\hline Non smoker & $44,005(71.1)$ & $142(66,277)$ & \multirow{3}{*}{0.026} & $166(72,367)$ & \multirow{3}{*}{0.015} \\
\hline Occasional smoker & $6376(10.3)$ & $140(66,276)$ & & $165(72,368)$ & \\
\hline Daily smoker & $11,523(18.6)$ & $139(61,294)$ & & $164(66,377)$ & \\
\hline \multicolumn{6}{|l|}{ Pre-pregnancy BMI } \\
\hline$<18.5 \mathrm{~kg} / \mathrm{m}^{2}$ & $1809(2.9)$ & $140(62,271)$ & \multirow{4}{*}{$<0.001$} & $168(71,376)$ & \multirow{4}{*}{$<0.001$} \\
\hline $18.5-24.9 \mathrm{~kg} / \mathrm{m}^{2}$ & $40,457(65.4)$ & $142(67,278)$ & & $167(74,368)$ & \\
\hline $25-29.9 \mathrm{~kg} / \mathrm{m}^{2}$ & $13,604(22.0)$ & $140(62,285)$ & & $163(67,372)$ & \\
\hline$\geq 30 \mathrm{~kg} / \mathrm{m}^{2}$ & $6034(9.7)$ & $137(58,288)$ & & $160(63,372)$ & \\
\hline \multicolumn{6}{|l|}{ Income } \\
\hline Both $<300,000$ NOK & $18,929(30.6)$ & $143(63,291)$ & \multirow{3}{*}{$<0.001$} & $167(69,371)$ & \multirow{3}{*}{0.073} \\
\hline One $\geq 300,000 \mathrm{NOK}$ & $26,419(42.7)$ & $142(65,283)$ & & $166(71,371)$ & \\
\hline Both $\geq 300,000 \mathrm{NOK}$ & $16,556(26.7)$ & $138(67,260)$ & & $164(74,363)$ & \\
\hline \multicolumn{6}{|l|}{ Milk and yogurt intake } \\
\hline$<200 \mathrm{~mL} /$ day & $17,187(27,8)$ & $88(49,141)$ & \multirow{3}{*}{$<0.001$} & $102(53,262)$ & \multirow{3}{*}{$<0.001$} \\
\hline 200-399 mL/day & $13,378(21.6)$ & $122(84,175)$ & & $137(88,296)$ & \\
\hline$\geq 400 \mathrm{~mL} /$ day & $31,339(50.6)$ & $183(123,320)$ & & $209(129,410)$ & \\
\hline \multicolumn{6}{|l|}{ Fish and seafood intake } \\
\hline$<20$ g/day & $14,195(22.9)$ & $117(49,252)$ & \multirow{2}{*}{$<0.001$} & $141(54,346)$ & \multirow{2}{*}{$<0.001$} \\
\hline$\geq 20 \mathrm{~g} /$ day & $47,709(77.1)$ & $148(74,286)$ & & $172(79,376)$ & \\
\hline \multicolumn{6}{|l|}{ Egg intake } \\
\hline$<8 \mathrm{~g} /$ day & $19,921(32.2)$ & $129(56,269)$ & \multirow{2}{*}{$<0.001$} & $153(61,357)$ & \multirow{2}{*}{$<0.001$} \\
\hline$\geq 8$ g/day & $41,983(67.8)$ & $146(71,283)$ & & $171(77,375)$ & \\
\hline \multicolumn{6}{|l|}{ Iodine from supplements } \\
\hline No & $42,329(68.4)$ & $141(65,279)$ & \multirow{2}{*}{$<0.001$} & $141(65,279)$ & \multirow{2}{*}{$<0.001$} \\
\hline Yes & $19,575(31.6)$ & $141(65,282)$ & & $252(122,466)$ & \\
\hline
\end{tabular}

* $p$-Values; unadjusted differences between groups. P5: 5th percentile, P95: 95th percentile.

In women who did not use iodine containing supplements and had low intake of milk/yogurt ( $<200 \mathrm{~mL} /$ day), $66.9 \%$ had iodine intake $<100 \mu \mathrm{g} /$ day and $98.6 \%$ had intake $<150 \mu \mathrm{g} /$ day. For comparison, in iodine supplement users with low milk/yogurt intake, the corresponding figures were $7.9 \%$ and $29.9 \%$. No women had iodine intake $<100 \mu \mathrm{g}$ /day if they obtained iodine from supplements and also consumed at least one daily serving of milk and/or yogurt.

Iodine from supplements contributed $19 \%$ and dairy products contributed $52 \%$ to the total iodine intake in the whole group. In women who did not obtain iodine from supplements, dairy products contributed on average $64 \%$ and seafood contributed $15 \%$ to the total iodine intake (Figure 1 ). 
Figure 1. The contribution (\%) to maternal iodine intake from food groups and iodine containing supplements in iodine supplement $(n=19,575)$ and non-supplement users $(n=42,329)$.

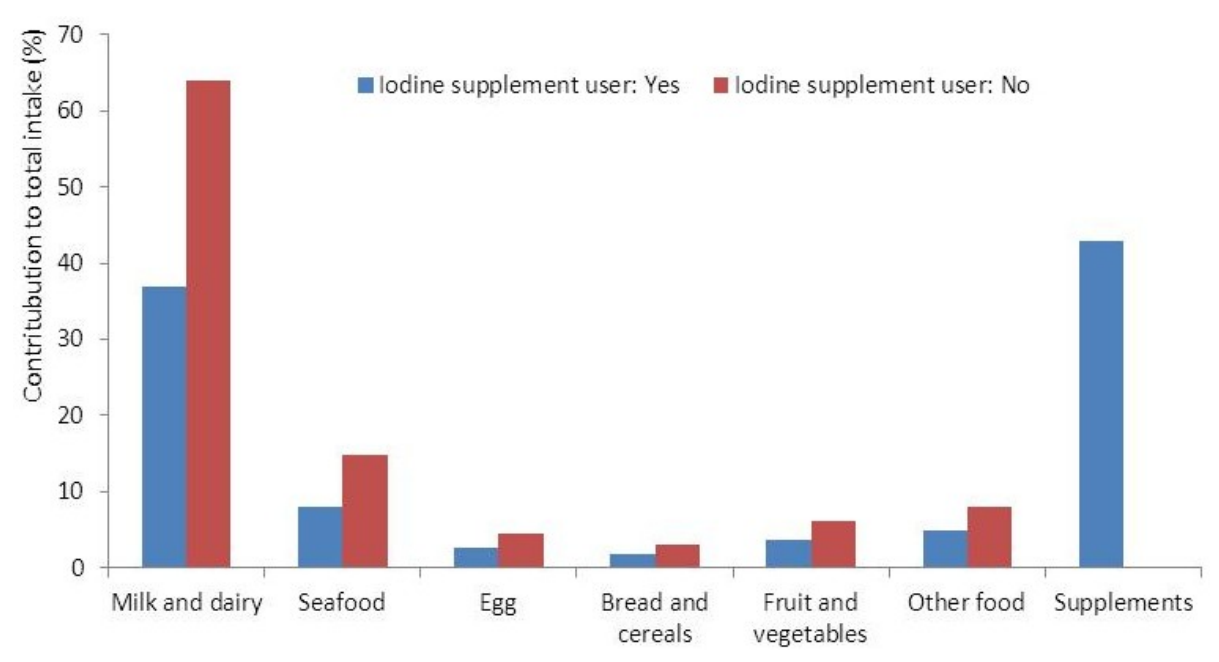

The prevalence of inadequate iodine intake decreased with increasing milk and yogurt consumption. The results indicate that an average milk/yogurt intake of 200-300 mL/day (1-2 servings) in addition to iodine from other foods, but no iodine from supplements, would secure $100 \mu \mathrm{g}$ iodine daily for most women, while higher milk and yogurt intake is needed to obtain $150 \mu \mathrm{g}$ iodine daily (Figure 2).

Figure 2. The prevalence of suboptimal $(<150 \mu \mathrm{g} /$ day $)$ and low $(<100 \mu \mathrm{g} /$ day $)$ iodine intake by increasing consumption of milk and/or yogurt in 42,329 non-iodine supplement users.

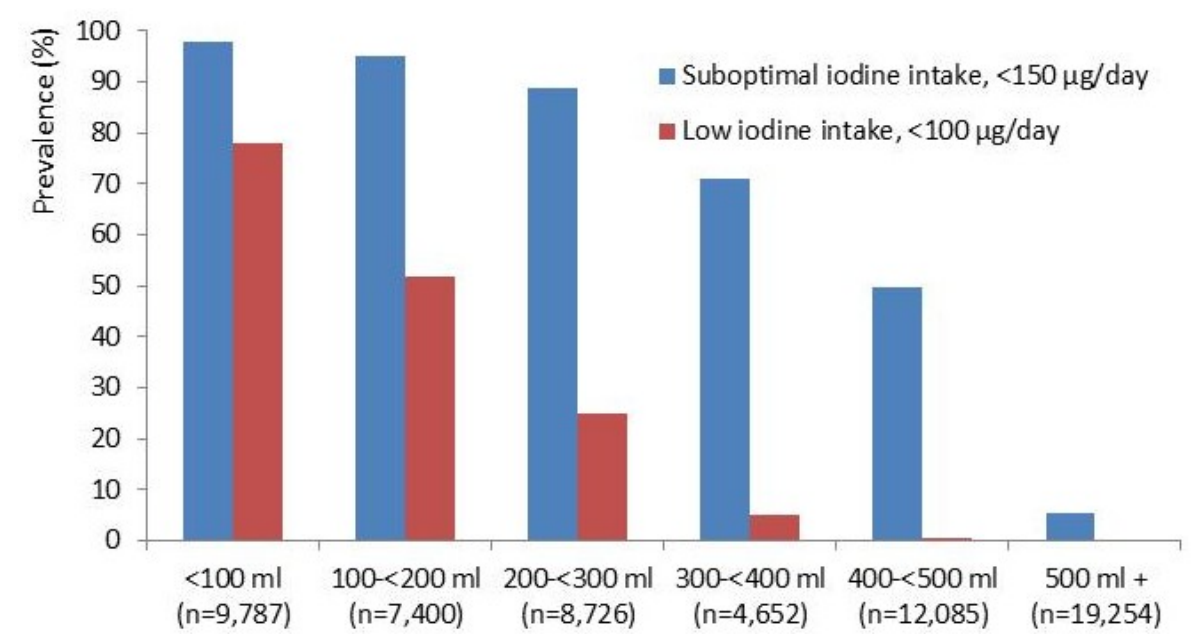

Likewise, the prevalence of inadequate iodine intake decreased with increasing intake of seafood. The results indicate that an average seafood intake of 20-40 g/day in addition to iodine from other foods, but no iodine from supplements, would secure $100 \mu \mathrm{g}$ iodine for most women (Figure 3 ). This amount corresponds to one daily portion of fish or other seafood on bread or 1-2 fish dinners weekly. 
Figure 3. The prevalence of suboptimal $(<150 \mu \mathrm{g} / \mathrm{day})$ and low $(<100 \mu \mathrm{g} / \mathrm{day})$ iodine intake by increasing consumption of seafood in 42,329 non-iodine supplement users.

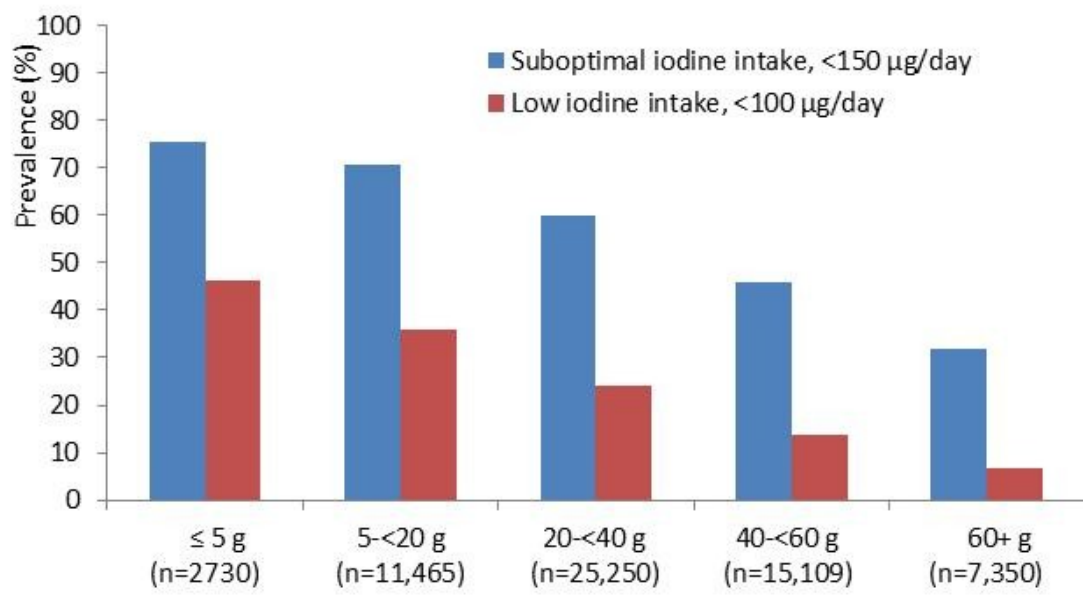

In the adjusted analysis, taking all maternal characteristic and relevant dietary practices into account, the most important predictors of suboptimal iodine intake were: no iodine supplement use, low consumption of milk and yogurt and low consumption of seafood (Table 3 ). These variables were identified as the major predictors of low iodine intake, also when inadequate iodine intake was defined as $<150 \mu \mathrm{g} /$ day (data not shown).

Table 3. Predictors of iodine intake $<100 \mu \mathrm{g} /$ day in 61,904 pregnant Norwegian women.

\begin{tabular}{|c|c|c|c|}
\hline & $\begin{array}{c}\text { Iodine }<100 \mu \mathrm{g} / \text { day } \\
n(\%) \\
\end{array}$ & $\begin{array}{c}\text { Unadjusted model } \\
\text { OR }(95 \% \mathrm{CI}) \\
\end{array}$ & $\begin{array}{c}\text { Adjusted model }^{1} \\
\text { OR (95\% CI) } \\
\end{array}$ \\
\hline \multicolumn{4}{|l|}{ Iodine from supplements } \\
\hline Yes & $419(2.1)$ & 1 & 1 \\
\hline No & $9533(22.5)$ & $13.3(12.0,14.7)$ & $58.6(52.0,66.2)$ \\
\hline \multicolumn{4}{|l|}{ Low milk/yoghurt intake } \\
\hline No: $\geq 200 \mathrm{~mL} /$ day & $1723(3.9)$ & 1 & 1 \\
\hline Yes: $<200 \mathrm{~mL} /$ day & $8229(47.9)$ & $22.9(21.7,24.3)$ & $42.2(39.4,45.7)$ \\
\hline \multicolumn{4}{|c|}{ Low fish and seafood intake } \\
\hline No: $\geq 20 \mathrm{~g} /$ day & $6093(12.8)$ & 1 & 1 \\
\hline Yes: $<20 \mathrm{~g} /$ day & $3859(27.2)$ & $2.6(2.4,2.7)$ & $3.8(3.5,4.1)$ \\
\hline \multicolumn{4}{|l|}{ Low egg intake } \\
\hline No: $\geq 8 \mathrm{~g} /$ day & $5584(13.3)$ & 1 & 1 \\
\hline Yes: $<8$ g/day & $4368(21.9)$ & $1.8(1.7,1.9)$ & $1.5(1.4,1.6)$ \\
\hline
\end{tabular}

To examine the possible change in dietary practices over time, we examined sources and intake of iodine by year of delivery for the women in our study (Table 4). The proportion of women having iodine intake below $100 \mu \mathrm{g}$ /day increased from $14.8 \%$ to $17.1 \%$ from 2002 to 2008 . There was also an increase in the proportion of women who obtained iodine from supplements. However, there was a $12 \%$ reduction in the median consumption of milk and yogurt, from $413 \mathrm{~mL} /$ day to $363 \mathrm{~mL} /$ day, and a corresponding reduction in iodine contributed by milk and yogurt. 
Table 4. Intake of iodine and selected iodine sources by year of delivery, $n=61,904$ pregnant women.

\begin{tabular}{lccccccc}
\hline \multicolumn{1}{c}{ Year } & $\mathbf{2 0 0 2}$ & $\mathbf{2 0 0 3}$ & $\mathbf{2 0 0 4}$ & $\mathbf{2 0 0 5}$ & $\mathbf{2 0 0 6}$ & $\mathbf{2 0 0 7}$ & $\mathbf{2 0 0 8}$ \\
\hline Number of women & 3997 & 10,552 & 11,020 & 11,286 & 11,921 & 10,246 & 2882 \\
Iodine $<100 \mu \mathrm{g} /$ day $(\%)$ & 14.8 & 15.6 & 16.2 & 15.9 & 15.7 & 16.3 & 17.1 \\
Iodine supplement use $(\%)$ & 26.5 & 25.8 & 31.6 & 34.5 & 34.7 & 32.9 & 31.5 \\
Iodine from food, median $\mu \mathrm{g} /$ day & 147 & 144 & 141 & 141 & 140 & 138 & 137 \\
Iodine from milk and yogurt, & 75 & 74 & 72 & 73 & 70 & 68 & 66 \\
median $\mu \mathrm{g} /$ day & & & & & & & \\
Iodine from other dairy products, & 14 & 14 & 14 & 14 & 14 & 14 & 14 \\
median $\mu \mathrm{g}$ /day & & & & & & & \\
Iodine contributed by seafood, & 23 & 22 & 21 & 20 & 20 & 19 & 19 \\
median $\mu \mathrm{g} /$ day & & & & & & & \\
Milk and yogurt, median mL/day & 413 & 409 & 402 & 408 & 400 & 381 & 363 \\
Seafood, median g/day & 35 & 34 & 33 & 33 & 33 & 33 & 32 \\
\hline
\end{tabular}

Urinary iodine concentration was measured in $24 \mathrm{~h}$ urine samples collected for $119 \mathrm{MoBa}$ participants in 2003-2004. Median UIC was $69 \mu \mathrm{g} / \mathrm{L}$ in the total sample, $64 \mu \mathrm{g} / \mathrm{L}$ in non-iodine supplement users $(n=84)$ and $84 \mu \mathrm{g} / \mathrm{L}$ in iodine supplement users. The corresponding median UIE was $130 \mu \mathrm{g} / 24 \mathrm{~h}$ in the total sample, $110 \mu \mathrm{g} / 24 \mathrm{~h}$ in non-iodine supplement users and $190 \mu \mathrm{g} / 24 \mathrm{~h}$ in iodine supplement users (Figure 4). Only $13(11 \%)$ of the women with available UIC data had UIC $\geq 150 \mu \mathrm{g} / \mathrm{L}$, while $106(89 \%)$ had UIC $<150 \mu \mathrm{g} / \mathrm{L}$. The median iodine intake in the 13 women with UIC $\geq 150 \mu \mathrm{g} / \mathrm{L}$ was $150 \mu \mathrm{g} /$ day, and the median intake in the 106 women with $\mathrm{UIC}<150 \mu \mathrm{g} / \mathrm{L}$ was $130 \mu \mathrm{g} /$ day. However, the WHO reference ranges for defining optimal iodine status based on UIC are for larger population groups [14].

Figure 4. Urinary iodine concentration (UIC, $\mu \mathrm{g} / \mathrm{L}$ ) and urinary iodine excretion (UIE, $\mu \mathrm{g} / 24 \mathrm{~h}$ ) in 119 pregnant women in the Norwegian Mother and Child Cohort Study.

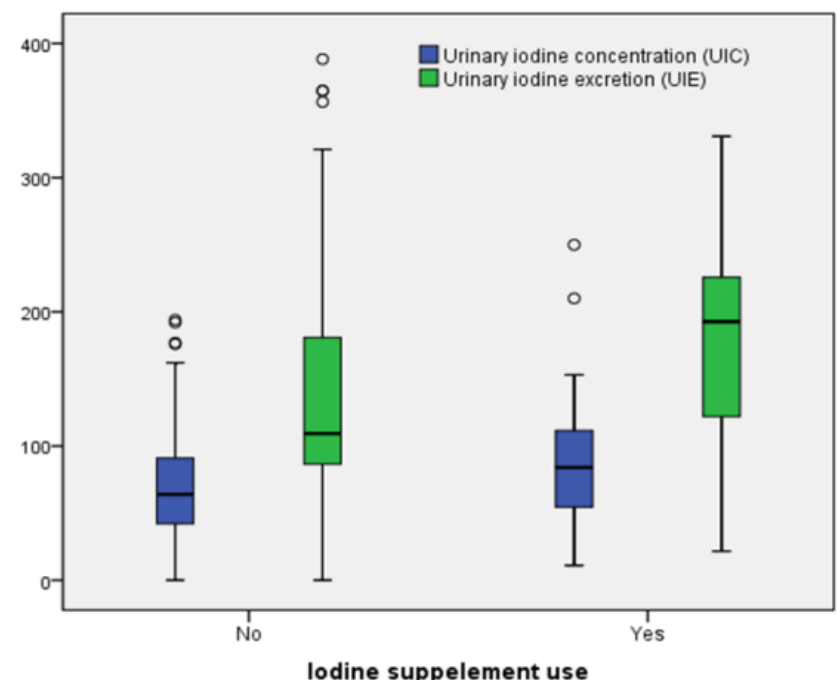

Box plot details: the horizontal line indicates the median; the box indicates the interquartile range (IQR) (IQR: 25th percentile to 75th percentile); the whiskers represent observations within 1.5-times the IQR; and the circles indicate observations more than 1.5-times the IQR away from the box, considered as outliers. 


\section{Discussion}

Although there is no screening program for iodine deficiency, Norway has been considered iodine replete for six decades. This study shows that inadequate iodine intake is prevalent in pregnant Norwegian women and suggests that iodine nutrition is a health concern. There are few dietary sources of iodine, and the individual intake of these food groups vary significantly. Pregnant women who do not consume or have low intake of dairy and/or seafood and who do not obtain iodine from supplements are at great risk of having inadequate iodine intake.

The use of an FFQ to assess iodine intake, as well as assigning an average iodine concentration to all milk and milk products, may result in imprecision in the intake estimates. However, in the present study, we based the estimates mainly on iodine concentrations measured in Norwegian food items and a detailed database for iodine content in specified dietary supplements. Data on urinary iodine excretion in a healthy and highly educated subsample of pregnant women supported that inadequate iodine intake should be regarded as a health concern also in Norway.

Low iodine intake in women of child-bearing age has been documented in other studies in Norway [27,30] and in other European countries [31-37]. Assessment of urinary iodine excretion in Western and Central Europe indicated that more than half of the population is at risk of iodine deficiency [2,38]. This is an issue of public concern, especially in regard to pregnant women [4]. A pilot study surveying the prevalence of iodine deficiency in the northeast of England concluded that $3.5 \%$ of the pregnant women had evidence of iodine deficiency and that $40 \%$ might be borderline deficient, defined by the urinary iodine/creatinine ratio [33]. Insufficient iodine nutrition in pregnant populations have been reported also in the US, New Zealand and Australia [39-41].

The effects of severe iodine deficiency during critical periods of brain development are well documented, while less is known about the consequences of milder forms of iodine deficiency [1,4,12,37,42]. Mild iodine deficiency may influence developmental impairment in children. Although limited, a few studies reported associations between prenatal iodine status or suboptimal maternal iodine intake and cognitive function of infants and children up to 18 months [43,44] and with attention deficit hyperactivity disorder (ADHD) symptoms in children [45,46]. A prospective study comprising 692 mother-children pairs in Holland reported an inverse association between maternal iodine status (UIC) and executive function in children at four years of age [47]. The median UIC in the Dutch study population $(203 \mu \mathrm{g} / \mathrm{L})$ did not suggest iodine insufficiency at the group level. In the subsample of women having urinary iodine measurements in our study, median UIC was much lower $(69 \mu \mathrm{g} / \mathrm{L})$. The detailed assessment of diet and supplement use in MoBa, along with an on-going ADHD sub-study involving clinical examination of three-year-old children with ADHD symptoms, represents a unique opportunity to investigate whether mild to moderate deficiency of iodine during pregnancy is associated with the risk of developing ADHD symptoms at three years of age. The MoBa study is especially suited to study potential associations between inadequate maternal iodine intake and ADHD in children, because the children are otherwise well nourished.

$\mathrm{MoBa}$ is a large pregnancy cohort with participants from both urban and rural regions, representing all age groups and all socioeconomic groups. The study group is not entirely representative of the whole pregnant population of Norway, being somewhat better educated and with a lower percentage of smokers than the overall population of pregnant women [48]. The study did not aim to include 
minority groups, and more than $99 \%$ of the participants are of Caucasian ethnicity. Thus, it is all the more remarkable that less than half of the study group had a total iodine intake equal to or above the recommended intake of $175 \mu \mathrm{g} / \mathrm{day}$, and it is likely that suboptimal iodine intake will be even more prevalent in the total population of pregnant Norwegian women. Data on urinary iodine concentration in the subsample corroborated that inadequate iodine status may be non-trivial even in a privileged pregnancy population in Norway. However, the WHO reference ranges for defining optimal iodine status are based on UIC for population medians [14,49]. The sample of 119 pregnant women is too small to evaluate iodine status in pregnant Norwegians in general, but the results indicate that suboptimal iodine nutrition is likely. Hence, iodine status should be assessed in a larger sample of pregnant women and in school children, as encouraged by WHO [14].

In this study, we combined food frequencies with iodine content measured primarily in Norwegian food samples. The highest iodine content was found in foods of marine origin, with lean fish, such as cod, having more than twice the content of fatty fish, such as farmed salmon [50]. The consumption of fish, especially lean fish, is declining, and more so in women than in men [51]. The current study showed that milk intake declined over the study period, resulting in a decline in iodine contributed by milk. The iodine content in milk differs with time of year and farming practice [26]. In Norway, low-fat milk from the summer season had significantly lower median iodine concentration (88 $\mu \mathrm{g} / \mathrm{L}$, range $63-122 \mu \mathrm{g} / \mathrm{L})$ compared with low-fat milk from the winter season $(232 \mu \mathrm{g} / \mathrm{L}$, range $103-272 \mu \mathrm{g} / \mathrm{L})$. The median iodine concentration of organic summer milk $(60 \mu \mathrm{g} / \mathrm{L})$ was significantly lower than the iodine concentration of organic winter milk (127 $\mu \mathrm{g} / \mathrm{L})$ [26]. A limitation of the present study was that a single average iodine value was applied to all milk and yogurt $(150 \mu \mathrm{g} / \mathrm{L})$. Changes in farming practices and legislation may have resulted in lower iodine content in milk over the last decade, but no values of iodine content in Norwegian milk have been published since 2003.

Estimating iodine intake using dietary assessment methods has limitations and uncertainties. The contribution of iodine from iodine fortified household salt was not included in the current study. However, the fortified salt contains very little iodine $(5 \mu \mathrm{g} / \mathrm{g})$, and the use of table salt is low $(<2 \mathrm{~g}$ /day). Other concerns related to estimating iodine intake are recall bias and changes in appetite and eating patterns due to pregnancy. Misreporting is a serious error in all dietary assessment, and recall of diet over the first trimester is particularly difficult, as many women experience nausea and changes in appetite and eating patterns. Results from the validation study showed that stronger agreement between the FFQ and the test methods was observed for foods perceived as "healthy" than for "unhealthy" foods. Likewise, stronger agreement was seen for total energy intake when we excluded women who reported nausea at the time of answering the FFQ [28]. It should also be noted that in this descriptive study, we used the MoBa FFQ to identify risk groups of low iodine intake, as well as to evaluate dietary sources of iodine, and these data are not independent. It is difficult to predict whether uncertainties in the dietary assessment would most likely lead to over- or under-estimating iodine intake. The results from the subsample analysis indicate that iodine intake of at least $150 \mu \mathrm{g} /$ day would be needed to get the median UIC up to the optimal range of $150-249 \mu \mathrm{g} / \mathrm{L}$ defined by WHO.

The results of the present study highlight the importance of a balanced diet, including milk and seafood, during pregnancy. The significance of these foods as iodine sources has also been reported in 
other Nordic countries [52-54]. Women with low intake of dairy and seafood are particularly vulnerable to low iodine intake and should be encouraged to use iodine-containing dietary supplements. Iodine fortification of table salt is a common strategy for iodine prophylaxis, but this does not ensure sufficient iodine intake in all population groups, except when iodine fortified salt, at concentrations higher than the $5 \mu \mathrm{g} / \mathrm{g} \mathrm{NaCl}$ presently permitted in Norway, also is used in bread and other food products [1]. Denmark implemented mandatory iodine fortification of household salt and bread salt at a level of $13 \mu \mathrm{g} / \mathrm{g} \mathrm{NaCl}(13 \mathrm{ppm})$ in the year 2000. The Danish iodine fortification program was monitored with regard to positive, as well as negative, health effects. Evaluation of urinary iodine excretion in subgroups of the population before and after fortification showed that fortification resulted in increased iodine intake in all investigated groups [53]. Milk was the strongest dietary determinant of iodine intake before, as well as after, the fortification, and subjects with low milk intake combined with low intake of bread or table salt had iodine intake below the recommended intake, also after fortification.

The importance of iodine-containing supplements has been demonstrated in studies using urinary iodine excretion for assessing sufficient iodine nutrition in pregnancy $[1,55]$. In Norway, the dietary recommendations to pregnant women do not include use of iodine supplementation. The present study shows that use of iodine-containing supplements is vital to secure optimal iodine intake and is especially important for women who do not include or have low intakes of seafood and/or milk and dairy in their diet.

\section{Conclusions}

In conclusion, this study shows that the current iodine intake in a large proportion of pregnant Norwegian women may give rise to concern. Although the evidence of deleterious effects in terms of subtle cognitive impairment is limited, it is essential to increase the public awareness of dietary iodine nutrition in pregnant women. Our results highlight the significance of a balanced diet, including milk and seafood, during pregnancy. Women with low intake of dairy and seafood are particularly vulnerable to low iodine intake and should be encouraged to use iodine-containing supplements. The dietary sources of iodine in Norway do not secure a sufficient iodine intake for the entire population, and more awareness on iodine nutrition is warranted, especially in women who, for various reasons, limit their consumption of dairy and seafood. It cannot be excluded that a number of children growing up in Norway today have lifelong impairments due to suboptimal iodine nutrition in early life. There is an urgent need for public health strategies to monitor and secure the iodine status in Norway.

\section{Acknowledgments}

The Norwegian Mother and Child Cohort Study is supported by the Norwegian Ministry of Health and the Ministry of Education and Research, NIH/NIEHS (contract no N01-ES-75558), NIH/NINDS (grant no.1 UO1 NS 047537-01 and grant no.2 UO1 NS 047537-06A1) and the Norwegian Research Council/FUGE (grant no. 151918/S10). We are grateful to all the participating families in Norway who take part in this on-going cohort study. 


\section{Conflict of Interest}

ALB, MH and HMM declare no conflict of interest. MHA is employed by TINE AS, which is a dairy company.

\section{References}

1. Delange, F. Iodine deficiency in Europe and its consequences: An update. Eur. J. Nucl. Med. Mol. Imaging 2002, 29, S404-S416.

2. Andersson, M.; Karumbunathan, V.; Zimmermann, M.B. Global iodine status in 2011 and trends over the past decade. J. Nutr. 2012, 142, 744-750.

3. Zimmermann, M.B.; Andersson, M. Assessment of iodine nutrition in populations: Past, present, and future. Nutr. Rev. 2012, 70, 553-570.

4. Skeaff, S.A. Iodine deficiency in pregnancy: The effect on neurodevelopment in the child. Nutrients 2011, 3, 265-273.

5. Andersson, M.; de Benoist, B.; Delange, F.; Zupan, J. Prevention and control of iodine deficiency in pregnant and lactating women and in children less than 2-years-old: Conclusions and recommendations of the Technical Consultation. Public Health Nutr. 2007, 10, 1606-1611.

6. Li, M.; Eastman, C.J. The changing epidemiology of iodine deficiency. Nat. Rev. Endocrinol. 2012, 8, 434-440.

7. Dahl, L.; Meltzer, H.M. The Iodine Content of Foods and Diets: Norwegian Perspectives. In Comprehensive Handbook of Iodine; Preedy, V.R., Burrow, G.N., Watson, R.R., Eds.; Academic Press: London, UK, 2009; pp. 345-352.

8. Frey, H.; Rosenlund, B.; Try, K.; Theodorsen, L. Urinary excretion of iodine in Norway. In Iodine Deficiency in Europe; Delange, F., Ed.; Plenum Press: New York, NY, USA, 1993; pp. 297-300.

9. Phillips, D.I. Iodine, milk, and the elimination of endemic goitre in Britain: The story of an accidental public health triumph. J. Epidemiol. Community Health 1997, 51, 391-393.

10. Zimmermann, M.B.; Andersson, M. Update on iodine status worldwide. Curr. Opin. Endocrinol. Diabetes Obes. 2012, 19, 382-387.

11. Zimmermann, M.B. The effects of iodine deficiency in pregnancy and infancy. Paediatr. Perinat. Epidemiol. 2012, 26, 108-117.

12. Zimmermann, M.B. Iodine deficiency in pregnancy and the effects of maternal iodine supplementation on the offspring: A review. Am. J. Clin. Nutr. 2009, 89, 668S-672S.

13. NNR Project Group. Iodine. In Nordic Nutrition Recommendations 2004, Integrating Nutrition and Physical Activity, 4th ed.; Becker, W., Alexander, J., Andersen, S., Aro, A., Fogelholm, M., Lyhne, N., Eds.; Nordic Council of Ministers: Copenhagen, Denmark, 2004; pp. 389-396.

14. World Health Organization; United Nations Children's Fund; International Council for Control of Iodine Deficiency Disorders. Assessment of Iodine Deficiency Disorders and Monitoring Their Elimination: A Guide for Programme Managers; World Health Organization: Geneva, Switzerland, 2007.

15. Zimmermann, M.B.; Jooste, P.L.; Pandav, C.S. Iodine-deficiency disorders. Lancet 2008, 372, $1251-1262$. 
16. Glinoer, D. The importance of iodine nutrition during pregnancy. Public Health Nutr. 2007, 10, 1542-1546.

17. Brantsæter, A.L.; Haugen, M.; Julshamn, K.; Alexander, J.; Meltzer, H.M. Evaluation of urinary iodine excretion as a biomarker for intake of milk and dairy products in pregnant women in the Norwegian Mother and Child Cohort Study (MoBa). Eur. J. Clin. Nutr. 2009, 63, 347-354.

18. Brantsæter, A.L.; Haugen, M.; Hagve, T.A.; Aksnes, L.; Rasmussen, S.E.; Julshamn, K.; Alexander, J.; Meltzer, H.M. Self-reported dietary supplement use is confirmed by biological markers in the Norwegian Mother and Child Cohort Study (MoBa). Ann. Nutr. Metab. 2007, 51, 146-154.

19. Haugen, M.; Brantsæter, A.L.; Alexander, J.; Meltzer, H.M. Dietary supplements contribute substantially to the total nutrient intake in pregnant Norwegian women. Ann. Nutr. Metab. 2008, 52, 272-280.

20. Magnus, P.; Irgens, L.M.; Haug, K.; Nystad, W.; Skjaerven, R.; Stoltenberg, C. Cohort profile: The Norwegian Mother and Child Cohort Study (MoBa). Int. J. Epidemiol. 2006, 35, 1146-1150.

21. Irgens, L.M. The medical birth registry of Norway. Epidemiological research and surveillance throughout 30 years. Acta Obstet. Gynecol. Scand. 2000, 79, 435-439.

22. Meltzer, H.M.; Brantsæter, A.L.; Ydersbond, T.A.; Alexander, J.; Haugen, M. Methodological challenges when monitoring the diet of pregnant women in a large study: Experiences from the Norwegian Mother and Child Cohort Study (MoBa). Matern. Child. Nutr. 2008, 4, 14-27.

23. Norwegian Institute of Public Health website. MoBa Food Frequency Questionnaire. Available online: http://www.fhi.no/dokumenter/253304bd64.pdf (accessed on 20 August 2012).

24. FoodCalc. Available online: http://www.ibt.ku.dk/jesper/foodcalc (accessed on 1 February 2005).

25. Norwegian Food Safety Authority. Norwegian Directorate of Health, Department of Nutrition-University of Oslo. Matvaretabellen 2006. Available online: http://www.matportalen.no (accessed on 1 October 2008).

26. Dahl, L.; Opsahl, J.A.; Meltzer, H.M.; Julshamn, K. Iodine concentration in Norwegian milk and dairy products. Br. J. Nutr. 2003, 90, 679-685.

27. Dahl, L.; Johansson, L.; Julshamn, K.; Meltzer, H.M. The iodine content of Norwegian foods and diets. Public Health Nutr. 2004, 7, 569-576.

28. Brantsæter, A.L.; Haugen, M.; Alexander, J.; Meltzer, H.M. Validity of a new food frequency questionnaire for pregnant women in the Norwegian Mother and Child Cohort Study (MoBa). Matern. Child. Nutr. 2008, 4, 28-43.

29. Brantsæter, A.L.; Haugen, M.; Thomassen, Y.; Ellingsen, D.G.; Ydersbond, T.A.; Hagve, T.A.; Alexander, J.; Meltzer, H.M. Exploration of biomarkers for total fish intake in pregnant Norwegian women. Public Health Nutr. 2010, 13, 54-62.

30. Dahl, L.; Meltzer, H.M.; Opsahl, J.A.; Julshamn, K. Iodine intake and status in two groups of Norwegians. Scand. J. Nutr. 2003, 47, 170-178.

31. Rasmussen, L.B.; Ovesen, L.; Bulow, I.; Jorgensen, T.; Knudsen, N.; Laurberg, P.; Pertild, H. Dietary iodine intake and urinary iodine excretion in a Danish population: Effect of geography, supplements and food choice. Br. J. Nutr. 2002, 87, 61-69.

32. Brussaard, J.H.; Brants, H.A.; Hulshof, K.F.; Kistemaker, C.; Lowik, M.R. Iodine intake and urinary excretion among adults in the Netherlands. Eur. J. Clin. Nutr. 1997, 51, S59-S62. 
33. Kibirige, M.S.; Hutchison, S.; Owen, C.J.; Delves, H.T. Prevalence of maternal dietary iodine insufficiency in the north east of England: Implications for the fetus. Arch. Dis. Child. Fetal. Neonatal. Ed. 2004, 89, F436-F439.

34. Limbert, E.; Prazeres, S.; Sao, P.M.; Madureira, D.; Miranda, A.; Ribeiro, M.; Jacome de Castro, J.; Carrilho, F.; Oliveira, M.J.; Reguengo, H.; et al. Iodine intake in Portuguese pregnant women: Results of a countrywide study. Eur. J. Endocrinol. 2010, 163, 631-635.

35. Andersson, M.; Aeberli, I.; Wust, N.; Piacenza, A.M.; Bucher, T.; Henschen, I.; Haldimann, M.; Zimmermann, M.B. The Swiss iodized salt program provides adequate iodine for school children and pregnant women, but weaning infants not receiving iodine-containing complementary foods as well as their mothers are iodine deficient. J. Clin. Endocrinol. Metab. 2010, 95, 5217-5124.

36. Lazarus, J.H.; Smyth, P.P. Iodine deficiency in the UK and Ireland. Lancet 2008, 372, 888.

37. Zimmermann, M.; Delange, F. Iodine supplementation of pregnant women in Europe: A review and recommendations. Eur. J. Clin. Nutr. 2004, 58, 979-984.

38. Vitti, P.; Rago, T.; Aghini-Lombardi, F.; Pinchera, A. Iodine deficiency disorders in Europe. Public Health Nutr. 2001, 4, 529-535.

39. Pettigrew-Porter, A.; Skeaff, S.; Gray, A.; Thomson, C.; Croxson, M. Are pregnant women in New Zealand iodine deficient? A cross-sectional survey. Aust. N. Z. J. Obstet. Gynaecol. 2011, 51, 464-467.

40. Travers, C.A.; Guttikonda, K.; Norton, C.A.; Lewis, P.R.; Mollart, L.J.; Wiley, V.; Wilcken, B.; Eastman, C.J.; Boyages, S.C. Iodine status in pregnant women and their newborns: Are our babies at risk of iodine deficiency? Med. J. Aust. 2006, 184, 617-620.

41. Caldwell, K.L.; Makhmudov, A.; Ely, E.; Jones, R.L.; Wang, R.Y. Iodine status of the U.S. population, National Health and Nutrition Examination Survey, 2005-2006 and 2007-2008. Thyroid 2011, 21, 419-427.

42. Gunnarsdottir, I.; Dahl, L. Iodine intake in human nutrition: A systematic literature review. Food Nutr. Res. 2012, 56, doi:10.3402/fnr.v56i0.19731.

43. Choudhury, N.; Gorman, K.S. Subclinical prenatal iodine deficiency negatively affects infant development in Northern China. J. Nutr. 2003, 133, 3162-3165.

44. Oken, E.; Braverman, L.E.; Platek, D.; Mitchell, M.L.; Lee, S.L.; Pearce, E.N. Neonatal thyroxine, maternal thyroid function, and child cognition. J. Clin. Endocrinol. Metab. 2009, 94, 497-503.

45. Velasco, I.; Carreira, M.; Santiago, P.; Muela, J.A.; Garcia-Fuentes, E.; Sanchez-Munoz, B.; Garriga, M.J.; Gonzalez-Fernandez, M.C.; Rodriguez, A.; Caballero, F.F.; et al. Effect of iodine prophylaxis during pregnancy on neurocognitive development of children during the first two years of life. J. Clin. Endocrinol. Metab. 2009, 94, 3234-3241.

46. Vermiglio, F.; Lo Presti, V.P.; Moleti, M.; Sidoti, M.; Tortorella, G.; Scaffidi, G.; Castagna, M.G.; Mattina, F.; Violi, M.A.; Crisa, A.; et al. Attention deficit and hyperactivity disorders in the offspring of mothers exposed to mild-moderate iodine deficiency: A possible novel iodine deficiency disorder in developed countries. J. Clin. Endocrinol. Metab. 2004, 89, 6054-6060. 
47. Van Mil, N.H.; Tiemeier, H.; Bongers-Schokking, J.J.; Ghabassian, A.; Hofman, A.; Hooijkaas, H.; Jaddoe, V.W.; de Muinck Keizer-Schrama, S.M.; Steegers, E.A.; Visser, T.J.; et al. Low urinary iodine excretion during early pregnancy is associated with alterations in executive functioning in children. J. Nutr. 2012, 142, 2167-2174.

48. Nilsen, R.M.; Vollset, S.E.; Gjessing, H.K.; Skjaerven, R.; Melve, K.K.; Schreuder, P.; Alsaker, E.R.; Haug, K.; Daltveit, A.K.; Magnus, P. Self-selection and bias in a large prospective pregnancy cohort in Norway. Paediatr. Perinat. Epidemiol. 2009, 23, 597-608.

49. Skeaff, S.A. Assessing iodine intakes in pregnancy and strategies for improvement. J. Trace Elem. Med. Biol. 2012, 26, 141-144.

50. Julshamn, K.; Dahl, L.; Eckhoff, K. Determination of iodine in seafood by inductively coupled plasma/mass spectrometry. J. AOAC Int. 2001, 84, 1976-1983.

51. Norwegian Scientific Committee for Food Safety Ad Hoc Group. A Comprehensive Assessment of Fish and Other Seafood in the Norwegian Diet; Norwegian Scientific Committee for Food Safety (VKM): Oslo, Norway, 2007.

52. Gunnarsdottir, I.; Gustavsdottir, A.G.; Steingrimsdottir, L.; Maage, A.; Johannesson, A.J.; Thorsdottir, I. Iodine status of pregnant women in a population changing from high to lower fish and milk consumption. Public Health Nutr. 2013, 16, 325-329.

53. Rasmussen, L.B.; Carle, A.; Jorgensen, T.; Knudsen, N.; Laurberg, P.; Pedersen, I.B.; Perrild, H.; Vejbjerg, P.; Ovesen, L. Iodine intake before and after mandatory iodization in Denmark: Results from the Danish Investigation of Iodine Intake and Thyroid Diseases (DanThyr) study. Br. J. Nutr. 2008, 100, 166-173.

54. Lamberg, B.A. Endemic goitre in Finland and changes during 30 years of iodine prophylaxis. Endocrinol. Exp. 1986, 20, 35-47.

55. Hess, S.Y.; Zimmermann, M.B.; Torresani, T.; Burgi, H.; Hurrell, R.F. Monitoring the adequacy of salt iodization in Switzerland: A national study of school children and pregnant women. Eur. J. Clin. Nutr. 2001, 55, 162-166.

(C) 2013 by the authors; licensee MDPI, Basel, Switzerland. This article is an open access article distributed under the terms and conditions of the Creative Commons Attribution license (http://creativecommons.org/licenses/by/3.0/). 